\title{
Rhabdomyomatosis of the heart associated with tuberous sclerosis. A case report and review of the literature
}

\begin{abstract}
Congenital heart rhabdomyomatosis is a rare condition that is associated in most cases with tuberous sclerosis, a genetic syndrome inherited with an autosomal dominant pattern. The last is caused by a mutation in tuberous sclerosis 1 or tuberous sclerosis 2 genes. We report a case of heart rhabdomyomatosis, associated with tuberous sclerosis. The lesion was discovered at 21 st week of gestation of a 36-year-old woman.

Keywords: prenatal diagnosis, cardiac rhabdomyomatosis, tuberous sclerosis, tuberous sclerosis gene 1, tuberous sclerosis gene 2
\end{abstract}

\section{Abbreviations \\ TSC: Tuberous Sclerosis}

\section{Introduction}

Rhabdomyomas, whilst are rare, they are the most common cardiac tumor in pediatric patients [1], accounting for $50-75 \%$. In a postnatal study [2] the referring cases where sporadic, associated with other cardiac anomalies or associated with tuberous sclerosis-approximately $50 \%$ of cases are associated with the disease [1]. The latter is a genetically inherited disease with an autosomal dominant pattern of inheritance and an incidence approaching 1:6000 births [3]. Mutation in TSC1 or TSC2 gene remains the main cause, with $60 \%$ of cases occurring de novo [3]. TS can affect all organs with skin, heart, brain, and kidneys being the most common targets. In this case we report the appearance of fetal heart rhabdomyomatosis associated with tuberous sclerosis and discovered during the routine follow up of the pregnancy.

\section{Case Report}

A 36-year-old female with subfertility and previous premature labor in $26^{\text {th }}$ week of gestation that leads in newborn's death decided to undergo in vitro fertilization. Her past medical history included cyst in the left ovary, leiomyoma of uterus and hypothyroidism treated with thyrohormone (25 mg per day). The embryo transfer was successful and the woman underwent the routine follow up. At the $21^{\text {st }}$ week of gestation ultrasound monitoring showed multiple nodules in the fetus heart without any other congenital abnormalities.

Embryo's heart ultrasound detected three hyperechogenic intracardial masses $(6-13 \mathrm{~mm}$ in diameter). The largest one occupied most of the left ventricle FIGURE 1a. The second one $(7 \mathrm{~mm}$ ) was near the tricuspid valve (with partial impairment of leaflet's opening) and the third one was at the interventricular septum of the aspect of the right ventricle (6 $\mathrm{mm}$ in diameter) FIGURE $1 \mathrm{a}$ and $\mathbf{1 b}$. Fetal cardiac function and size were normal. No associated cardiac anomaly was detected. The fetal cranial sonographic examination was normal.

After prenatal counseling for genetic disorders and amniocentesis, the result of the genetic analysis confirmed the diagnosis of tuberous sclerosis. The genetic test detected in the male fetus c. $1716+2 \mathrm{~T}>\mathrm{G}$ mutation of TSC2 gene in a heterozygotic pattern. The parents decided to terminate the pregnancy at $23^{\text {rd }}$ week of gestation and the embryo was sent for histological examination.

The autopsy revealed a male embryo, without any congenital malformations, weighing $660 \mathrm{gr}$ with $34 \mathrm{~cm}$ crown-heel length, $22 \mathrm{~cm}$ crownrump length and foot length $5 \mathrm{~cm}$. After dissection of the body, the extraction of the heart
Kouroupi Maria ${ }^{1 *}$, Alexiadis Triantafyllos², Karamanidis Dimitrios ${ }^{3}$, Koutsougeras

Gerasimos ${ }^{3}$, Giatromanolaki Alexandra ${ }^{1}$ and Lambropoulou Maria ${ }^{2}$

${ }^{1}$ Department of Pathology, Democritus University of Thrace, University Hospital of Alexandroupolis, Greece ${ }^{2}$ Laboratory of Histology-Embryology, Medical Department, Democritus University of Thrace, Greece ${ }^{3}$ Department of Obstetrics and Gynecology, University Regional Hospital of Alexandroupolis, Greece

*Author for correspondence:

marykouroupi@gmail.com 

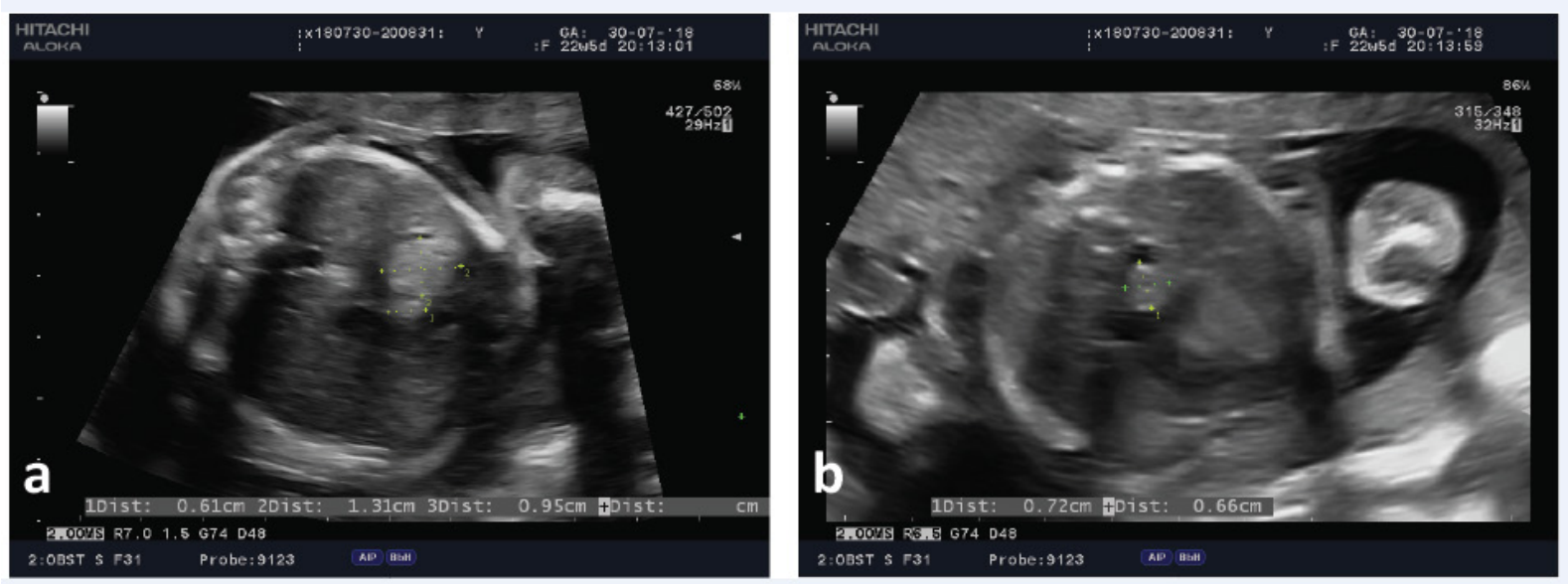

FIGURE 1. (a): Two round homogeneous hyperechogenic masses $(6.1 \mathrm{~mm}$ and $13.1 \mathrm{~mm})$. The largest protruded in the left ventricle and the small one in the interventricular septum; (b): Cardiac rhabdomyoma $7.2 \mathrm{~mm}$ near the tricuspid valve.
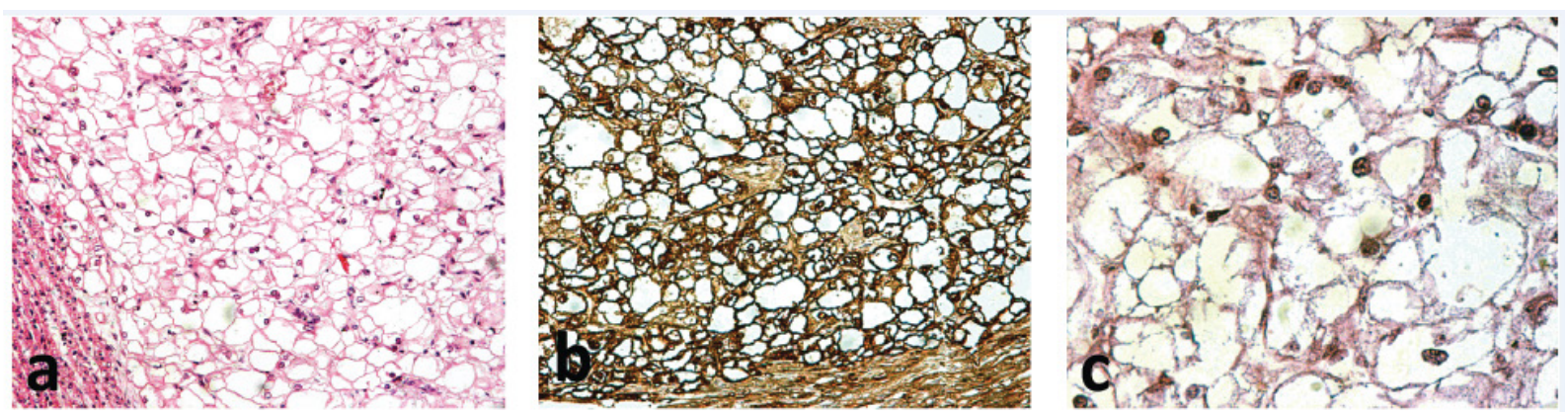

FIGURE 2. Microscopic examination of the tumor. (a): "spider" cells with vacuolated cytoplasm (haematoxylin-eosin, x20 magnification); (b): positive immunohistochemical reactivity for myoglobin (x20 magnification); (c): distinct cytoplasmic extensions (histochemical stain PTAH, x60 magnification).

was performed. Its dimensions were $4 \times 3 \times 2$ $\mathrm{cm}$ and weighted $7 \mathrm{gm}$. Cardiac sections showed coagulated blood in right atrium, right ventricle and left atrium. Three firms, well-circumscribed whitish nodules, $0.6 \mathrm{~cm}, 0.7 \mathrm{~cm}$ and $1.2 \mathrm{~cm}$ in diameter, respectively were observed. The smallest one was in the interventricular septum at the aspect of the right ventricle, while the other two protruded in the cavity of the left ventricle, pushing the interventricular septum towards right ventricle. In the abdomen, there was an insignificant peritoneal effusion, while sections of all other organs did not show any macroscopic lesions.

Series of sections from these cardiac nodules were obtained and examined. Microscopically, typical findings of rhabdomyoma were noticed. The tumor cells, the so-called spider cells FIGURE 2a, were large with vacuolated cytoplasm full of glycogen (Periodic acid-Schiff reactivity), some of which had a polygonal shape, centrally located nucleus and distinct cytoplasmic extensions (designated with histochemical stain PTAH). FIGURE 2b Immunohistochemical investigation of the neoplasm showed reactivity for myoglobin FIGURE 2c and myoD1, as well as focal positivity to desmin. Proliferation index MIB-1 was minimal.

\section{Discussion}

Rhabdomyoma is a rare benign tumor of striated muscle fibers, even though some support it as being as hamartoma rather than a true neoplasm [3]. Even though its rarity, it is the most common cardiac tumor, accounting for more than $50 \%$ of benign cardiac neoplasms $[1,4]$. The first reported case was in 1862 [5]. It can occur sporadically [6,7] some appear with other congenital heart disease [8], or in association with tuberous sclerosis $[1,8,9]$ in a rate around $50-60 \%[1,3]$.

Usually, it is developed in ventricles with the left one being the most common location. There are reported cases in septum [10] and in intrapericardial space.

Diagnosis is made with ultrasound or/ and Magnetic Resonance Imaging (MRI) 
[11] during the third trimester of gestation, between 27 and 36 weeks or in early neonatal period $[8,12]$. Ultrasound features consist of a round homogeneous hyperechogenic mass, predominately in ventricles. Pericardial teratoma, fibroma, hemangioma, myxoma, and echogenic cardiac focus should be considered in the differential diagnosis. Symptoms of this entity depend on the size and the location of the tumor.

In intrauterine life they cause echocardiograph changes [13], arrhythmias, hydrops [8] or nothing. Postnatal, infants can be asymptomatic or only having a murmur, whilst some of them suffer from congestive heart failure, severe arrhythmias or even sudden death $[3,14]$. Cardiac rhabdomyomas may continue to grow postpartum, due to maternal estrogen. The later decrease in the size of the tumor may be due to reduced estrogen levels [15]. These tumors are at their largest in fetal life, then shrink with age and may even disappear completely. The prevalence is, therefore, higher in children than in adults. Surgical resection should be performed if cardiac function is adversely affected [16].

Macroscopically, they are well-circumscribed, without capsule surrounding, gray-white, firm, small nodules with an average size from millimeters to several centimeters, embedded in the myocardium or protruding in cardiac cavities [17]. It can reach up to $10 \mathrm{~cm}$ in diameter and often are multiple. The term rhabdomyomatosis refer to numerous nodules that are not greater than $1 \mathrm{~mm}$ in diameter.

Microscopically [17], the tumor consists of clusters of large polygonal to rounded cells ("spider cells") with vacuolated cytoplasm full of glycogen deposits (PAS-diastase positive histochemical stain) separated by strands of cytoplasm extending between cell membrane and nucleus, without any mitotic activity. Immunohistochemical investigation [17] reveals reactivity to striated muscle cells antigens, such as myoglobin, actin, desmin, vimentin, and variable to HMB45, although S-100 protein is negative.

Early recognition is really important in order to investigate any connection with tuberous sclerosis [18-20] and to plan treatment after birth, which includes surgery if patient's life is threatened [21,22] and drugs, such as everolimus $[3,23,24]$. It is worth mentioning that some masses regress spontaneously after birth $[8,25]$ while other investigators believe that the younger the age of the diagnosis, the greater the chance for regression [3].

Tuberous sclerosis is an autosomal dominant inherited disease which affects males and females equally. It is due to mutations of TSC1 and TSC2 gene which are located at chromosome $9 \mathrm{q} 34$ and $16 \mathrm{p} 13$, respectively, with $60 \%$ of cases to be due to de novo mutations [3]. The disease targets almost all organs such as brain, lungs, heart, kidneys, bone, eyes and skin. The clinical manifestations include seizures, hydrocephalus, mental retardation, rhabdomyomas [21], renal angiomyolipomas [11], developmental delay, spine malformations and skin angiofibromas [26]. Some authors focus on prenatal diagnosis of tuberous sclerosis [11,20] and especially the recognition of cardiac rhabdomyomas $[1,27]$ since it is the commonest presentation. Concerning the disease's therapy and management, there is huge progress [28], with mTORC1 inhibitors to be in the forefront [29].

In a meta-analysis, Chao et al. [30] reported that most cardiac rhabdomyomas were detected after the $24^{\text {th }}$ gestational week and only $13.7 \%$ of the cases were detected before the $24^{\text {th }}$ gestational week. There have been many cases reported of rhabdomyomas/rhabdomyomatosis connected with tuberous sclerosis [31,22] diagnosed prenatally and in the postnatal period, such as a giant rhabdomyoma [24,32,33] neonatal intracardiac rhabdomyomatosis and a case of diffuse rhabdomyomatosis without any distinct mass formation [34]. There are cases with rhabdomyomatosis of lung [35-37] and meninges [38]. To the best of our knowledge there is only one case of tuberous sclerosis and heart rhabdomyoma in a patient with trisomy 21 [19,39]. Rhabdomyomas usually develop in the left ventricle, but there is a case reported in the right ventricle [40], in the right atrium of a patient suffering from Wolff Parkinson White syndrome [41] and a case occurring in both ventricles and right atrium without any connection with tuberous sclerosis [22].

\section{Conclusion}

Since heart rhabdomyomas/ rhabdomyomatosis is one of the most prominent clinical manifestations in patient with tuberous sclerosis, an early diagnose is critical for the patient itself as well as for the family members since it is a congenital disease. 


\section{REFERENCES}

Bussani R, Rustico MA, Silvestri F. Fetal cardiac rhabdomyomatosis as a prenatal marker for the detection of latent tuberous sclerosis. Pathol Res Pract. 197, 559-561 (2001).

Burke AP, Virmani R. Cardiac rhabdomyoma: A clinicopathologic study. Mod Pathol. 4, 70-74 (1991).

Lezzi F, Quarti A, Capestro A, et al. Evolution of a rare ECG pattern $\mathrm{n}$ an aggressive case of neonatal tuberous sclerosis complex. $N t$ J Case Rep. 44, 197-201 (2018).

Paladini D, Palmieri S, Russo MG, et al. Cardiac multiple rhabdomyomatosis: prenatal diagnosis and natural history. Ultrasound Obstet Gynecol. 7, 84-85 (1996).

von Recklinghausen F. Negotiations of the society for obstetrics, Mr. v. Recklinghausen puts the heart of a newborn. Monatsschr Geburtsk. 20, 1-2 (1862).

Freymann R, Oelert H, Kallfelz HC. Rhabdomyomatosis of the heart and ventricular septal defect. Z Kardiol. 66, 35-38 (1977).

Bassareo PP, Fanos V, Tavera MC, et al. Left ventricular giant rhabdomyoma in an infant with no tuberous sclerosis: accidental finding and complex management. Turk J Pediatr. 52, 420-422 (2010).

Fuller MY, Wolf DA, Buja LM. Sudden death in a 15-year-old with diffuse cardiac rhabdomyomatosis: an autopsy case report. Cardiovascular Pathol. 23, 351-353 (2014).

Tworetzky W, McElhinney DB, Margossian $\mathrm{R}$, et al. Association between cardiac tumors and tuberous sclerosis in the fetus and neonate. Am J Cardiol. 92, 487-489 (2003).

Fesslova V, Villa L, Rizzuti T, et al. Natural history and long-term outcome of cardiac rhabdomyomas detected prenatally. Prenat Diagn. 24, 241-248 (2004).

Filipová H, Procházka $M$, Vrtěl R. Diagnosis of tuberous sclerosis complex focusing on prenatal period. Ceska Gynekol. 81, 147-154 (2016).

Pipitone S, Mongiovi M, Grillo R, et al. Cardiac rhabdomyoma in intrauterine life: clinical features and natural history. A case series and review of published reports. Ital Heart J. 3, 48-52 (2002).

Aslan E, Sap F, Sert A, et al. Tuberous sclerosis and cardiac tumors: new electrocardiographic finding in an infant. Tex Heart Inst J. 41, 530-532 (2014).

Fenoglio JJ, MCAllister HA, Ferrans VJ.
Cardiac rhabdomyoma: a clinicopathologic and electron microscopic study. Am J Cardiol. 38, 241-251 (1976).

Bader RS, Chitayat D, Kelly E, et al. Fetal rhabdomyoma: prenatal diagnosis, clinical outcome and incidence of associated tuberous sclerosis complex. J Pediatr. 143, 620-624 (2003).

Butany J, Nair V, Naseemuddin A, et al. Cardiac tumors: diagnosis and management. Lancet Oncol. 6, 219-228 (2005).

Travis WD, Brambilla E, Burke AP, et al. WHO classification of tumours of lung, pleura, thymus and heart. International Agency for Research on Cancer, Lyon. J Thorac Oncol. 10, 1243-1260 (2015).

Chitayat D, McGillivray BC, Diamant $S$, et al. Role of prenatal detection of cardiac tumours in the diagnosis of tuberous sclerosisreport of two cases. Prenat Diagn. 8, 577-584 (1988).

Gamzu R, Achiron R, Hegesh J, et al. Evaluating the risk of tuberous sclerosis in cases with prenatal diagnosis of cardiac rhabdomyoma. Prenat Diagn. 22, 1044-1047 (2002).

Degueldre SC, Chockalingam P, Mivelaz Y, et al. Considerations for prenatal counselling of patients with cardiac rhabdomyomas based on their cardiac and neurologic outcomes. Cardiol Young. 20, 18-24 (2010).

Jimenez CS, Benito BF, Sanchez F-BC. Cardiac rhabdomyomas in tuberous sclerosis: clinical symptoms and course in 18 cases diagnosed in childhood. An Esp Pediatr. 52, 36-40 (2002).

Choong CS, Liew KL, Tsai MJ, et al. Neonatal intracardiac rhabdomyomatosis: A case report. Zhonghua Yi Xue Za Zhi (Taipei). 61, 362-366 (1998).

Aw F, Goyer I, Raboisson MJ, et al. Accelerated cardiac rhabdomyoma regression with everolimus in infants with tuberous sclerosis complex. Pediatr Cardiol. 38, 394-400 (2017).

Colaneri M, Quarti A, Pozzi M. Everolimus-induced near-resolution of giant cardiac rhabdomyomas and large renal angiomyolipoma in a newborn with tuberous sclerosis complex. Cardiol Young. 26, 10251028 (2016).

Chen X, Hoda SA, Edgar MA. Cardiac rhabdomyoma. Arch Pathol Lab Med. 126, 1559 (2002).

Charbonneau S, Giroux L, Vauclair R, et al. Cardiac rhabdomyomas and aortic valve atresia: An unusual association. Ann Pathol. 6, 206-210 (1986).

Atalay S, Aypar E, Ucar T, et al. Fetal and neonatal cardiac rhabdomyomas: clinical presentation, outcome and association with tuberous sclerosis complex. Turk J Pediatr. 52, 481-487 (2010).

Samueli S, Abraham K, Dressler A, et al. Tuberous Sclerosis Complex: new criteria for diagnostic work-up and management. Wien Klin Wochenschr. 127, 619-630 (2015).

Wataya-Kaneda M, Uemura M, Fujita $\mathrm{K}$, et al. Tuberous sclerosis complex: Recent advances in manifestations and therapy. Int $\mathrm{J}$ Urol. 24, 681-691 (2017).

Chao AS, Chao A, Wang TH, et al. Outcome of antenatally diagnosed rhabdomyoma: case series and a meta-analysis. Ultrasound Obstet Gynecol. 31, 289-295 (2008).

Kelekci S, Yazicioglu HF, Yilmaz B, et al. Cardiac rhabdomyoma with tuberous sclerosis: A case report. J Reprod Med. 50, 550-552 (2005).

Abdel-Rahman U, Ozaslan F, Esmaelli A, et al. A giant rhabdomyoma with left ventricular inflow occlusion and uninventrcular physiology. Thorac Cardovasc Surg. 53, 259260 (2005).

Schlaegel F, Takacs Z, Solomayer EF, et al. Prenatal diagnosis of giant cardiac rhabdomyoma with fetal hydrops in tuberous sclerosis. J Prenat Med. 7, 39-41 (2013).

Shrivastava S, Jack JJ, White RS, et al. Diffuse rhabdomyomatosis of the heart. Arch Pathol Lab Med. 101, 78-80 (1977).

Hardisson D. Histogenesis of striated muscle cells in the newborn lung parenchym (rhabdomyomatosis), lung morphogenesis and development. Pathol Res Pract. 195, 725-726 (1999).

Chen MF, Onerheim R, Wang NS, et al. Rhabdomyomtosis of newborn lung: a case report with immunohistochemical and electromicroscopic characterization of striated muscle in the lung. Pediatr Pathol. 11, 123-129 (1991).

Hardisson D, Garcia-Jimenez JA, JimenezHeffernan JA, et al. Rhabdomyomatosis of the newborn lung unassociated with other malforamations. Histopathology. 31, 474-479 (1997).

Jarrell HR, Krous HF, Schochet SS. Meningeal rhabdomyomatosi. Arch Pathol Lab Med. 105, 387 (1981). 
Krapp M, Baschat AA, Gembruch U, et al. Tuberous sclerosis with intracardiac rhabdomyoma in a fetus with trisomy 21: Case report and review of literature. Prenat Diagn. 19, 610-613 (1999). de Almeida EC, Leite MS, da Silva MA, et al. Right ventricular rhabdomyoma causing pulmonary stenosis. Arq Bras Cardiol. 60, 417429 (1993).
Venugopalan P, Babu JS, Al-Bulushi A. Right atrial rhabdomyoma acting as the substrate for Wolff-Parkinson-White syndrome in a 3-month-old infant. Acta Cardiol. 60, 543-545 (2005). 